that 51 per cent. had developed some form of recurrence or extension; secondary or tertiary surgery was necessary in two-thirds of these to check the progress of the disease and maintain useful hand function. He concludes that surgery alone cannot be expected to produce routine cures.

Millesi, following unoperated patients with mild Dupuytren's contracture for from 6 to 12 years, found that $46 \cdot 5$ per cent. had developed evidence of further activity or extension. He suggests that the course of the disease is not significantly altered by non-surgical treatment by such agents as vitamin $\mathrm{E}$, ultrasonics and radiotherapy, which give much the same proportion of patients whose disease is progressive. Surgery itself, by whatever method, would seem only to buy time for the patient. Against this are to be set the sometimes crippling complications of surgery (reviewed by Tubiana and Thomine).

The reader will find an interesting contribution by Thomine on the palmar fascia studied microscopically in early foetal hands and an important review by Gosset on the gross morbid anatomy of the contracture, but he will not find any review of the epidemiology of this condition, its associated diseases, or any adequate study of its untreated natural history.

A. ST. J. Dixon.

Synovectomy and Arthroplasty in Rheumatoid Arthritis. (2nd International Symposium, January 27-29, 1967, Basel, Switzerland.) Edited by G. Chapchal. 1967. Pp. 131, 66 figs. Thieme, Stuttgart.

The 2nd symposium held by the Orthopaedic Department of the University of Basel was devoted to the question of synovectomy and arthroplasty in rheumatoid arthritis. The collected short papers give a good idea of achievements to date in this increasingly important branch of rheumatology and orthopaedic surgery, together with problems which await solution, such as the need for further technical advances in various forms of arthroplasty and the exact value of synovectomy in preventing the progression of joint damage.

Contributions are of uneven standard but the small book is well produced and contains a useful if not lavish number of illustrations. It will form a serviceable source of reference for physicians and surgeons working in this field. J. T. Scotr.

\title{
HEBERDEN SOCIETY
}

\section{ANNUAL REPORT, 1967}

At the Annual General Meeting held on November 17, 1967, the President, Dr. Oswald Savage, was in the chair.

The following new members were elected:

Ordinary Members (from Associate Members):

Dr. P. H. N. Wood, Dr. S. Mattingly, Dr. P. Holt, Dr. P. Boardman, Dr. A. K. Thould, Dr. J. Holborow, Dr. S. D. Roberts, Dr. D. A. Pitkeathly, Prof. C. H. Barnett, Dr. W. W. Buchanan, Dr. B. McConkey, Dr. D. L. Gardner, Dr. A. Myles.

Associate Members:

Dr. P. D. Fowler, Dr. W. M. Zinn, Dr. W. C. Walker, Dr. E. R. Bickerstaff, Dr. R. J. Francois, Dr. M. K. Jasani, Dr. A. W. T. Eade, Dr. Mary Corbett, Mr. G. P. Arden, Dr. C. G. Barnes, Dr. P. A. Bacon, Dr. U. Steiger, Dr. C. H. Lack, Dr. I. M. Roitt, Dr. N. Williamson, Dr. P. D Byers.
Associate Members (Overseas):

Dr. L. Hall, Dr. M. I. Bruk, Dr. J. Forster.

Temporary Visitor Members:

Dr. J. M. Thompson, Dr. H. Little, Dr. T. M. Scott, Dr. M. Robertson.

The President recorded with regret the deaths of Dr. H. Gibson, a member since 1947, and also of Mr. R. Rendell who had acted as Honorary Auditor to the Society.

\section{Activities}

The first Clinical meeting of the year was held on March 17, 1967 at the Royal National Orthopaedic Hospital, Stanmore. The meeting included a Symposium on the Physiology of Bone (Annals, 26, 565).

The Heberden Round was conducted by Dr. B. M. Ansell at the Canadian Red Cross Memorial Hospital, Taplow, on June 17. A full report of the papers and demonstrations at this meeting begins on p. 282 . 
The Heberden Oration for 1967 was delivered by Dr. L. E. Glynn at the Royal College of Physicians, London, on November 17. He took as his subject "The Chronicity of Inflammation and its Significance in Rheumatoid Arthritis" (Annals, 27, 105).

The Annual Dinner was held on November 17, at the Royal College of Physicians. Among the guests were a number of French doctors and their wives together with the President of the Royal College of Physicians.

The Annual General Meeting took place at the Royal College of Physicians on November 17 and 18. A full report of the Scientific Sessions begins on p. 287.

\section{Grant-in-Aid}

The Society acknowledges with appreciation the renewal of the grant from the Arthritis and Rheumatism Council, which enabled the Society to continue its activities.

\section{"Annals of the Rheumatic Diseases" \\ Full reports of the Society's activities have appeared regularly in the Annals of the Rheumatic Diseases.}

\section{Library}

The Honorary Librarian, Dr. W. S. C. Copeman, reported as follows:

Last year it was decided that modern books and pamphlets and other items relating to rheumatology should be collected, in the belief that certain of these would in due course acquire historic interest. Thus about forty items have been received and added to the library. The librarian is grateful to all those members and others who have contributed.

In addition, 56 of our old leather-bound volumes have been treated with the British Museum dressing through the courtesy of Mr. L. M. Payne, Librarian of the Royal College of Physicians, who has put much time and expertise at our disposal, and in whose charge the Library is kept. To him we are very grateful. The Wellcome Library has also generously rebound or repaired six valuable books, through the good offices of its Director and Chief Librarian, Dr. F. N. L. Poynter, to whom also we are grateful. A further framed colour print (1816) has been presented by Professor E. G. L. Bywaters for the Heberden Room in the College.

Books of historical interest on our subject are becoming very rare, chiefly owing to the increasing interest of collectors in the U.S.A. The committee therefore appeal to members of the Society to establish a library fund from which such items could be purchased when they come on the market.

A number of books and engravings of Franco-British interest were put on view during the Society's Annual General Meeting and Dinner in the Royal College of Physicians, and attracted much interest.

The two earliest known publications on the Gout (1534 and 1537) referred to in last year's report have been translated from mediaeval German through the Wellcome Museum (by courtesy of Dr. Poynter) and will shortly be published.

\section{Additions during 1967}

L'actualité rhumatologique. 1966, (par les médecins du Centre Viggo Petersen), sous la direction de S. de $\frac{\bar{s}}{\frac{5}{T}}$

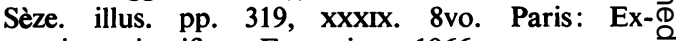
pansion scientifique Française. 1966.

Arthritis and Rheumatism Council for Research in Great Britain and the Commonwealth. (Formerly The $\vec{\circ}$ Empire Rheumatism Council). Annual report, 1953/二 54-1962, 1964-1965. illus., ports., diagrs. 8vo. $\vec{\omega}$ London. 1954-1962, 1964-1965.

Bunim, J. J., and others. Morceaux choisis sur les généralités et principales formes des rhumatismes inflammatoires cryptogénétiques. (Monographies. internationales de rhumatologie, 1). pp. 144. 8vo. $\omega$ Paris: Expansion scientifique Française. 1965.

Burgauer, Dominicus. $\mathrm{Ob}$ das Podagra moglich $\mathrm{zu}_{\frac{1}{\sigma}}^{\oplus}$ generen oder nit. Nutzlich zu wissen allen denen,o die damit behafft. 1111. 4to. Strasbourg: M. Apiarius. 1534.

Early tract on gout by a physician. The oldest in the library.

Burt, Hugh Armitage. See Kensington Borough. First $\vec{c}$ annual report on the Chronic Rheumatism Scherfe $\mathrm{e}_{\infty}$ of the Royal Borough of Kensington, by J. Fent W. S. C. Copeman, and H. A. Burt. (1939).

Cecchi, Elvio. See Lucherini, T., and Cecchi, E. Protlemi di patologia dell'istoreattività. 1952.

Cecchi, Elvio. See Lucherini, T., and Cecchi, E. Terapia delle malattie ruematiche. 1963.

Cecchi, Elvio. See Lucherini, T., and Cecchi, E. Trattato $\overrightarrow{\vec{F}}$ di reumatologia. 1954.

Centre de Rhumatologie Viggo Petersen. See Actualité. L'actualité rhumatologique. 1966.

Cervini, Claudio. See Lucherini, $T$, and Cervini, $C$. Reumatismo e gravidanza. 1951 .

Cervini, Claudio. See Lucherini, T., and Cervini, $C . \bar{\varrho}$ La spondilite auchilosante, 1955.

Copeman, William Sydney Charles. The chronic diseases. in the World War, 1939-1945. Repr. from Ann. rheum. Dis., vol. 5, 1946, pp. 17-19.ß

Copeman, William Sidney Charles. Rheumatism in음 Sweden. Repr. from Ann. rheum. Dis., vol. 5, 1946, pp. 115-121.

Copeman, William Sidney Charles. See also Kensington Borough. First annual report of the Chronic Rheu- $N$ matism Scheme of the Royal Borough of Kensington, by J. Fenton, W. S. C. Copeman, and H. A. Burt. స్
(1939).

Copeman, William Sidney Charles. See also St. Charles'ত্ Hospital, London. Report for year ending Decro ember 31, 1932, by P. I. Kaufman and W. S. C. Copeman. (1933).

Empire Rheumatism Council. See Arthritis and Rheumatism Council for Research in Great Britain and the Commonwealth. 
Fenton, James. See Kensington Borough. First annual report on the Chronic Rheumatism Scheme of the Royal Borough of Kensington, by J. Fenton, W. S. C. Copeman, and H. A. Burt. (1939).

Fox, Robert Fortescue. Arthritis in women: a clinical survey ... also a suggestion for setting up rest houses for rheumatoid arthritis. Founded on a lecture delivered at the Institute of Hygiene, London, April, 1936. tables. pp. iii, 35. 8vo. London: H. K. Lewis, 1936.

Françon, François (1888- ). Osteoarthritis of the hip. (Folia rheumatologica, no. 9). illus, tables. diagrs. pp. 16. 8vo. Basle: J. R. Geigy. 1966. Rev. repr. of Documenta rheumatologica (Acta rheumatologica), no 9, 1956. With ten additional copies in French, Spanish, Italian, Portuguese, Swedish, Norwegian, Danish, German, Dutch, Turkish.

Gardner, Dugald Lindsay. Pathology of the connective tissue diseases. illus. pp. $\mathrm{x}, 456$. 8vo. London: Arnold. 1965.

Glyn, John Howard, and others. Low incidence of osteoarthritis in hip and knee after anterior poliomylitis: a late review. Repr. from Brit. med J., 1966, vol. 2, pp. 739-742.

Golding, Douglas Noel. A synopsis of rheumatic diseases. pp. viii, 192. 8vo. Bristol: J. Wright. 1966.

Heberden Society, London. Annual report, 1964-1965. ports. 8vo. London. The Society. 1964-1965.

International League against Rheumatism. See Ligue Internationale contre le Rhumatisme.

Kaufmann, Phyllis Irene. See St. Charles' Hospital, London. Report for year ending December 31, 1932, by P. I. Kaufmann and W. S. C. Copeman. (1933).

Kensington Borough. First annual report on the Chronic Rheumatism Scheme of the Royal Borough of Kensington, by J. Fenton, W. S. C. Copeman, and H. A. Burt. illus, tables, diagr. fol. (London: The Royal Borough of Kensington, 1939.)

Lancen, Serge. See Ligue Internationale contre le Rhumatisme. Repertus fons remedii ... (n.d.)

Ligue Internationale contre le Rhumatisme. The campaign against rheumatism: retrospect and outlook. pp. ii, 14. 4to. (London: 1937.)

A draft of what would have been the first appeal for public funds in the cause of rheumatism by the International League against Rheumatism.

Ligue Internationale contre le Rhumatisme. Repertus fons remedii: marche triumphale de la Ligue Internationale contre le Rhumatisme, by $\mathrm{S}$. Lancen. (Music and words.) pp. 2. 8vo. Deventer: N. V. Nourypharma. (n.d.)

Lucherini, Tommaso (1891-1967). Reumatologia practica per medici e studenti. plates, diagrs. pp. XIv, 482, 1 1. 8vo. Roma: Società Editrice Universo. 1956.

Lucherini, Tommaso (1891-1967), and Cecchi, Elvio. Problemi di patologia dell'istoreattivita. col. plates. pp. viii, 189, 1 1. 8vo. Roma: Abbruzzini. 1952.
Lucherini, Tommaso (1891-1967), and Cecchi, Elvio. Terapia delle malattie reumatiche. illus., tables. pp. 185, 1 1. 8vo. Napoli: Edizioni Scientifiche Italiane, 1963.

Lucherini, Tommaso (1891-1967), and Cecchi, Elvio. Trattato di reumatologia. (Collana di clinica medica.) 2 vols. plates, tables, diagrs. 8vo. Milano: Francesco Vallardi. 1954.

Lucherini, Tommaso (1891-1967). and Cervini, Claudio. Reumatimso e gravidanza. plates. 1 1., pp. 138, 1 1. 8vo. Roma: Edizioni Mediche Scientifiche. 1951.

Lucherini, Tommaso (1891-1967), and Cervini, Claudio. La spondilite anchilosante. plates, (some col.), tables. pp. 469. 8vo. Roma: Edizioni Mediche e Scientifiche. 1955.

Lucherini, Tommaso (1891-1967), and Schiavetti, L, La malattia reumatoide: aspetti medico-sociali. (I problemi della sicurezza sociale collana.) tables. diagrs. pp. 92. 8vo. Roma: Instituto Nazionale per l'Assicurazione contro le Malattie. 1961.

Lucherini, Tommaso (1891-1967), and others. Semeiotica delle malattie reumatiche. (Premio Internazionale Acqui di Reumatalogia, 1951). plates, (some col.), tables, diagrs. pp. XVI, 344, 211. 8 vo. Roma: Abbruzzini. 1951.

Paris. Hôpital Lariboisière. Centre de Rhumatologie Viggo Petersen. See Actualité. L'actualité rhumatologique. 1966.

Reiter, Hans. Reiter-Syndrom und Reitersche Krankheit im Urteil bekannter Fachkollegen des In-und Auslandes. Med. Welt, bd. 18 (NF), 1967. pp. 1-48.

St. Charles' Hospital, London. Report for year ending December 31, 1932, by P. I. Kaufmann and W. S. C. Copeman, table. pp. 3. 8vo. (London: St. Charles' Hospital. 1933.)

Schiavetti, L. See Lucherini, T., and Schiavetti, L. La malattia reumatoide. 1961.

Sèze, Stanislas de. See also Actualité. L'actualité rhumatologique. 1966.

Verantworttung. Eyn verantworttung Podagrae vor dem Gichter: ober vilfaltige Klage der armen Podagrischen rott. $16 \mathrm{ll}$. (last bl.) 4to. Mainz: J. Schaffer. 1537. (Anon).

This tract is remarkable for its fine woodcuts, the second showing a group of old men, all sufferers from gout.

West London Hospital. Department of Rheumatic Diseases. Annual report, 1945-1953. illus., ports., tables, diagrs. 8vo. London. 1945-1953.

World Health Organization. Expert Committee on Rheumatic Diseases. First report. (World Health Organization technical report series, no. 78). pp. 29. 8vo. Geneva: World Health Organization. 1954. 


\section{Miscellaneous Material}

Postage Stamps. Issued in connexion with the 6th European Congress of Rheumatology, 1967.

Three stamps unused, and on envelope addressed to Dr. W. S. C. Copeman; 1, 2, and 5 escudos.

Engraving. "A German present" depicting the Prince Regent suffering with Gout. By C. Williams (1816) in colour.

Presented by Professor E. G. L. Bywaters.

\section{OFFICERS AND COMMITTEE, 1968}

President: Dr. J. J. R. Duthie, F.R.C.P.E., Northern General Hospital, Edinburgh, 5.

President-Elect: Dr. A. G. S. Hill, M.C., F.R.C.P.E., Rheumatism Research Centre, Stoke Mandeville Hospital, Aylesbury, Bucks.

Hon. Treasurer: Dr. F. Dudley Hart, F.R.C.P., Westminster Hospital, London, S.W.1.

Senior Hon. Secretary: Dr. A. J. Popert, M.R.C.P., St. John's Hospital, Droitwich Spa, Worcs.

Junior Hon. Secretary: Dr. W. R. M. Alexander, F.R.C.P.E., Rheumatic Unit, Northern General Hospital, Edinburgh.

Hon. Librarian: Dr. W. S. C. Copeman, C.B.E., T.D., F.R.C.P., 129 Harley Street, W.1.

General Secretary: M. C. G. Andrews.

Members of the Executive Committee:

DR. J. T. ScotT, M.R.C.P., Charing Cross Hospital, London, W.C.2.

DR. V. Wright, M.R.C.P., Rheumatism Research Unit, Medical School, Leeds, 2.

DR. D. A. Brewerton, M.R.C.P., 4 Woodhall Avenue, Dulwich, S.E.21.

DR. C. F. Hawkins, F.R.C.P., Rheumatism Research

Wing, Queen Elizabeth Hospital, Birmingham, 15.

DR. J. A. Cosh, F.R.C.P., Royal National Hospital for Rheumatic Diseases, Bath.

DR. K. W. WAlton, Ph.D., M.D., Rheumatism Research Wing, Dept. of Experimental Pathology, The Medical School, Birmingham, 15.

\section{PROGRAMME FOR 1968}

March 22: The Heberden Round, Queen Elizabeth Hospital, Birmingham, by invitation of Dr. C. F. Hawkins.

May 17: Glasgow.

June 27/29: Burgenstock, Switzerland.

November 22/23: The Heberden Oration (Dame Honor B. Fell, F.R.S.). Annual General Meeting and Dinner.

Titles and short programme notes of original communications which Members wish to make to the Society during 1968 should be sent to the Senior Honorary Secretary (Dr. A. J. Popert, St. John's Hospital, Droitwich Spa, Worcs.) at least one month before the date of the meeting.

Abstracts for subsequent publication in the Annals of the Rheumatic Diseases (approximately 300 words) should be sent in advance or handed to the Secretary at ithe (Meeting. Members ?are asked to prepare these abstracts for publication in such a way as to show their methods and results, so that the subsequent discussion of a paper can be related to its contents.
Clinical Meeting.-The following papers were read $\frac{\text { D }}{\widetilde{D}}$ on June 17, 1967, at the Canadian Red Cross $\frac{5}{3}$ Memorial Hospital, Taplow:

Dissociation of Anti-inflammatory from Analgesic $\overrightarrow{\vec{F}}$ Activity of Drugs used in Rheumatoid Arthritis, by $\stackrel{\oplus}{\oplus}$ P. L. Boardman and F. Dudley Hart (Westminster Hospital, London): The aim of this study was to establish a method for measuring joint size by a technique based $\frac{\bar{F}}{\Gamma}$ on the use of standard jewellers' rings under controlled $\stackrel{\complement}{\complement}$ conditions; to differentiate reduction of swelling, an index of anti-inflammatory activity, from pain relief or analgesic effect; and to assess some factors responsible $\vec{\circ}$ for variation and error. Four trials were reported:

(1) Comparison of prednisone $(7.5 \mathrm{mg}$. daily) with $\vec{\omega}$ placebo to assess the effect of a known anti-inflammatory agent.

(2) Comparison of paracetamol (6 g. daily) withis placebo to assess the effect of a known analgesic agent. $v$

(3) Comparison of high dosage of salicylate $(5 \cdot 3 \mathrm{~g} \cdot \mathrm{N}$ daily) with low dosage $(2 \cdot 6 \mathrm{~g}$. daily).

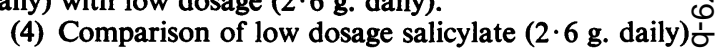
with placebo.

All patients had rheumatoid arthritis. The trial was designed in the form of a double-blind cross-over, each $z$ treatment period being 7 days. Assessment was by joint size, grip strength and preference. The results were plotted sequentially, based on the changes in joint size

Prednisone reduces joint size compared with placeba $; \infty$ there is no difference between paracetamol and place in effect on joint size; high dosage salicylate redua so joint size compared with low dosage; there is no diafi erence between low dosage salicylate and placebo in theiro effect on joint size.

The effects on grip strength and preference were also@ analysed.

The use of sequential analysis and its advantages and음 potential disadvantages were discussed. Reasons for the $-\overrightarrow{-}$ short duration of the trial were given. The effect on joint size estimates of time of day, observer variation, exercise, and heat and also the nature of the alteration in joint size was discussed and it was concluded that the latter represented inflammatory tissue change.

These findings were considered to be important for the following reasons:

(1) Salicylates may be administered in high dosage for anti-inflammatory effect.

(2) The method of measuring joint size is accurate under defined conditions with double-blind control.o The change following an anti-inflammatory agent is so small that such factors as the time of day or variationo between observers may introduce errors that are greater than the actual changes.

(3) The unrestricted use of supplementary salicylates ${ }^{\omega}$ in trials may affect the results obtained.

(4) It is suggested that this is a suitable method for theo assessment of the anti-inflammatory activity of rapidlyacting drugs.

Discussion.-DR. A. ST. J. Dixon (Bath): Have you음 any information on the results of varying the ring size ${ }^{\circ}$ 
DR. BOARDMAN: We have results in a small number of patients, but there were only three or four and we did not get much change in joint size-not the 3 or $4 \mathrm{~mm}$. reached in the trial.

DR. V. WRIGHT (Leeds): I am not clear why an observer without practice should have such a different reading of joint size nor am I clear how the grip strength was measured-you mentioned $3,500-4,500$ but I wonder what these units are. I should also be interested to know at what time in the morning and the evening the measurements were taken and should be grateful if you could amplify what you found with heat. Dr. Plunkett, working in our Unit, has shown recently by volumetric studies that after wax baths patients show a marked increase in swelling of the hands, yet improve in grip strength. Did you find this?

DR. BoARDMAN: The observer difference may be to some extent positional. It may also be due to the pressure with which the ring was pushed over the knuckle. The measurements were taken at 9.00 a.m. and 6.00 p.m. This was a group of eight rheumatoid patients and the grip strength was measured in millimetres with both hands added together over the whole group. Joint size changes after heat and exercise were estimated in relatively few patients. The heat was only local heat to the hand, measuring it in water as warm as they could stand comfortably for a limited period of 2 minutes, and localized exercise changes were estimated after exercising the hands maximally for the same 2-minute period.

Dr. T. M. Chalmers (Edinburgh): Have you any information on the effect of practice?

Dr. BoARdMAN: The crieteria for this trial were based on findings in in-patients, and we found in in-patients over a 10-day period that the grip strength and joint size improved, which may be due to the admission to hospital or perhaps to learning. We think that these effects are excluded in this trial because of the baseline period, in that these patients were measured weekly and that the baseline was not just one week but they were kept until the joint size and changes were standardized at less than $4 \mathrm{~mm}$. and the grip strength at less than 50 $\mathrm{mm}$. Hg.

DR. C. J. M. Clark (Bournemouth): Would you be able to distinguish reversible and irreversible swelling?

Dr. Boardman: No. Except that the patients all demonstrated a response to prednisone, it was otherwise impossible to differentiate reversible from irreversible swelling.

Dr. A. K. Thould (Truro): Did you take into account the effect menstruation might have on finger size?

Dr. Boardman: No., but the patients in the trial had a mean age of about 43 and I can think of only two to whom this might have been applicable.

Dr. Dudley HarT: In clinical trials you are allowed to give the patient as much aspirin as you like and the amount given is sometimes not stated; the useful point has emerged from this study that, if the patient receives enough salicylate, this can affect the tissue, not only as regards the analgesic effect but, as regards the swelling too.

Re-appraisal of the Radiological Changes in Ankylosing Spondylitis with Respect to the Age at Onset, Duration, and Type of Disease, by M. J. RiLeY, B. M. Ansell, and E. G. L. BywATERS (Taplow): Using a special proforma, radiographs of patients diagnosed as suffering from ankylosing spondylitis have been re-assessed independent of the identity of the subject. Particular note has been made as to the character of the syndesmophyte formation, involvement of the apophyseal joints, ligamentous calcification, and the state of the vertebral bodies and discs. These features were correlated with the age at onset and duration of the disease, as well as associated disorders such as ulcerative colitis and psoriasis.

Discussion.-Dr. O. Savage (London): How do you define a Romanus lesion?

DR. RILEY: We took two things as Romanus lesions: (1) a sclerotic appearance at the upper or lower anterior border of a vertebra and (2) surface erosions seen either at the upper or lower border. We did not include as a Romanus lesion one case in which there was a fluffy appearance along the whole upper border of the vertebra.

DR. V. WRIGHT (Leeds): What was your reproducibility, and as regards wedging did this relate to therapy?

Dr. RILEY: We did not relate any of the findings to therapy. We have not been through them all two or three times, but of the forty or fifty looked at in 1965 we reviewed about thirty again and the reproducibility was fairly good. I have not worked out the exact figure.

Dr. F. Dudley HaRT (London): What was the age scatter of those with onset under the age of 16 ?

DR. F. D. HarT (London): What was the age scatter of those with onset under the age of 16 ?

Dr. RILEY: There were five with onset under the age of 10, the youngest being 7 years old. The commonest age at onset was about 13 or 14 years.

Dr. M. Wilkinson (Perth): At about what age could you diagnose with confidence changes in sacro-iliac joints in these young patients?

DR. RILEY: This is very difficult. We were of course doing this retrospectively, but at 10 years all the ones we said were included in the ankylosing spondylitics had obvious sacro-iliitis at that time too. Amongst cases of Still's disease there is quite a high incidence of sacro-iliac change anyway.

Dr. W. MARTEL (U.S.A.): Do they go on to complete bony ankylosis? Is there any difference in appearance?

Dr. RILEY: In the Taplow series studied by Dr. Carter and her colleagues, there were three main lesions: simple fusion, erosive changes, and typical ankylosing spondylitis changes going on to fusion. These were exactly the same in every case of ankylosing spondylitis.

DR. D. J. WARD (Oswestry): When did you stop calling them cases of Still's disease and diagnose ankylosing spondylitis?

Dr. RILEY: Officially in 1965 . Only eleven of those under 16 had been diagnosed as cases of Still's disease here. Of the group as a whole, eighteen had been diagnosed as Still's disease, and these developed back symptoms and a diagnosis of ankylosing spondylitis from 5 to 10 years after the onset, the mean being 9 years. The few other patients who had not been labelled as cases of Still's disease developed the back symptoms and were rediagnosed 1 to 8 years after the onset, the mean being 4 years.

DR. J. J. R. DUTHIE (Edinburgh): We are accustomed to regard ankylosing spondylitis as essentially seronegative, and we are also aware that when what we call juvenile arthritis becomes adult they tend to develop 
positive sheep cell agglutination test. Have you any information on this series?

Dr. B. M. Ansell (Taplow): We only found one patient positive once. There were some 340 investigations in ten cases of Still's disease who developed ankylosing spondylitis, with only one result with a titre as high as $1: 16$, the FII and latex tests being negative. We regard this case as sero-negative. Our juvenile patients with Still's disease do not become sero-positive as they grow up.

The Early Lesion of Ankylosing Spondylitis, by E. G. L. Bywaters (Taplow): Published pathological descriptions of ankylosing spondylitis have concerned late cases. The early lesion, before the development of bony ankylosis, is described in two cases dying of amyloidosis at the ages of 21 and 22 years.

Changes were seen primarily to concern cartilage at its junction with vascularised tissues and resembled in many ways those of polychondritis. Calcification and ossification, illustrated by material from 18 post-mortem cases, are late and secondary changes.

Discussion.-DR. G. N. MYERS (Harrogate): I noticed that these were all sagittal slides. Did you look at the onco-vertebral joints?

Prof. Bywaters: We have not yet looked at the oncovertebral joints in these two cases; but at this age they are only just beginning to appear and are not real joints. Usually there is not much change.

A Computer-assisted Analysis of the Radiographic Neck Lesions in Chronic Rheumatoid Arthritis, by WILLIAM J. PARK (St. George's Hospital, London), and W. O'BRIEN, W. J. Hollingsworth, and G. de Forest (Connecticut, U.S.A.): The neck radiographs of 100 adult patients with rheumatoid arthritis of more than 10 years' duration were studied and matched for age and sex with a control group. All known neck lesions were examined and graded, using plain radiographs, tomography, and cine radiography, and the results were analysed by computer to determine:

(1) If rheumatoid arthritis of the neck and degenerative changes could be differentiated radiologically and statistically;

(2) To predict those patients at risk from neurological complications or death.

Using Fisher's discriminant function, a score was obtained for the neck readings and plotted in graph form. The score was also correlated with the patient's other abnormalities, and those with high scores were found to have more severe generalized disease and to be significantly anaemic. The scores of the control group were lower than those of the rheumatoid arthritics. A cut-off point was obtained above which no control patients were found.

There is good evidence from autopsy examinations that atlanto-axial subluxation is a major factor in contributing to neurological complications and death.

A regression analysis was performed to determine the lesions with the highest correlations with atlanto-axial subluxation. There were found to be vertebral plate erosion, subluxation, and apophyseal joint erosion.

It was concluded that patients with these lesions in a gross form were in danger of severe atlanto-axial sub- luxation, and that management of chronic rheumatoid arthritis should include serial radiography of the neck.

Discussion.-DR. J. S. LAWRENCE (Manchester): I 므. think it should be pointed out that, although cervical ? changes are related to this very typical joint disease, one $\vec{F}$ may get changes without evidence of peripheral rheuma- $\stackrel{S}{\longrightarrow}$ toid arthritis, and these people are very seldom referred to hospital. They are treated with aspirin and rub along.

DR. PARK: I would agree with that.

DR. V. WRIGHT (Leeds): I should like to ask how you arrive at your weightings for each assessment and what you do to standardize the magnification in the neck, because you can alter the measurement of an $x$ ray of the atlanto-occipital separation by magnification by as much as 2 or $3 \mathrm{~mm}$.

DR. PARK: This is a recognized statistical tool and we used it as such.

DR. A. Kates (London): Would you say that we ought to be thinking about changing our ideas of the type of iv case that physicians would recommend for fusion?

Dr. PARK: I think that this is a very valuable point. By the time neurological signs appear, anatomical disease would make operation hazardous. In fact, one of our patients died on the operating table, we were never able to establish definitely why. She had extreme atlantoaxial subluxation.

DR. W. MARTEL (Ann Arbor, Michigan, U.S.A.): I was much interested in this study. We performed a similar sort of evaluation 5 years ago, utilizing 100 consecutive $\vec{c}$ clinic patients with rheumatoid arthritis who had cervicad of involvement, and we found very much the same sort of $\infty$ thing. There were some neurological manifestations but they were relatively unimpressive and showed littes correlation with the degree of atlas dislocation. We thought at the time that this descrepancy was related to the slow development of these lesions and to the fact that there was extensive destruction of bone, allowing for $\mathbb{D}$ more room for the spinal cord. Since then, however, we have come to realize that fatal cases of cervical dis- $\overline{\bar{O}}$ location do occur among these patients and that protec- $\frac{0}{3}$ tive measures should be taken in their management. $\vec{T}$ Furthermore, although the degree of dislocation at the atlanto-axial level is usually the most dramatic, subluxations do occur at other levels and may be equally important. Also, there is often involvement of the oncovertebral joints and we have observed secondary attenu- $\bar{\sigma}$ ation in the calibre of the vertebral artery adjacent to such 3 involvement. There may be extreme destruction of the intervertebral joints so that changes may be expected in the relationship of the intervertebral foramina and the nerve roots and radicular arteries.

Finally, as to the question of magnification, in a practical sense this plays no real role. Although there $\frac{D}{0}$ is always a magnification factor, this varies from approximately 10 to 20 per cent. and depends on the object-film $N$ and the tube-object distances. In the usual range of $O$ medical radiography, these distances vary only slightly. $N$ When one is dealing with a measurement of 1 or $2 \mathrm{~mm}$., $\mathrm{N}$ there is little difference whether the magnification factor $\mathrm{\omega}$ is 10 or 20 per cent. in actual clinical practice. It is important to appreciate, however, that cervical dis- 0 locations may not be detected unless the patient is examined with head flexion.

Prof. E. G. L. BYwaters (Taplow): Does angiography give you further information on the distortion of the $\square$ vertebral arteries resulting from atlanto-axial subluxa- 0 tion? 
DR. W. MARTEL: We have not had a wide experience with vertebral angiography in rheumatoid disease, so I cannot comment on the effect of atlas displacement on the vertebral arteries. I would imagine that if the displacement were severe enough, there might be compression of the vertebral arteries. Some observations have been made in Sweden and displacement of the vertebral arteries in association with atlas displacement was apparently seen without attenuation in the calibre of the vessels. I do not, however, know any of the details regarding these cases, nor in fact, how many such cases were involved.

Problems of Still's Disease in Adult Life, by U. Steiger (Basel) (introduced by B. M. Ansell). Published in the Annals (1968), 27, 146.

Hypermobility Syndrome: Musculo-skeletal Symptoms associated with Generalized Hypermobility of Joints, by J. A. KIRK, B. M. ANSEll, and E. G. L. Bywaters (Taplow). Published in the Annals (1967), 26, 419.

Immunological Sex Differences, by $K$. RHoDES, $A$. ScotT, R. MARKhAM, and E. Monk-Jones (Royal Free Hospital, London): Primary antibody responses to Brucella vaccine were studied in 300 adult subjects, of whom 103 had classical or definite rheumatoid arthritis, 91 were healthy first-degree relatives of the patients, and 106 were controls matched for sex and age. The proportions of males and females were equal.

Female patients, relatives, and controls all produced higher mean levels of specific antibody to Brucella than the corresponding males, and the overall sex difference in antibody response was statistically highly significant $(P<\cdot 001)$. The highest mean titres were present in female patients. No differences in antibody production were observed between patients, relatives and controls.

Mean levels of immunoglobulin $\mathbf{M}$ were also significantly higher $(\mathrm{P}<\cdot 001)$ in females compared with males, and female patients had the highest levels. No changes were detected following Brucella injection, compared with pre-injection levels.

No significant sex differences were observed in IgG and IgA levels. Patients had significantly higher mean IgG, IgM, and IgA levels than non-patients.

Erythrocyte sedimentation rates showed a steeper rise in female relatives and controls compared with male, after the injection. No significant change was detected in the patients.

Sheep cell agglutination tests measuring rheumatoid factor showed significant increases in titre in patients, relatives and controls, and in both sexes.

These findings, suggestive of greater immunological competence in females, were briefly discussed in the light of the increased female incidence of rheumatoid disease.

Discussion.-DR. W. R. M. AleXANDER (Edinburgh): You said that the sheep cell titre rose after immunization, and yet you had no change in level of IgM, from which one would assume that the IgM representing rheumatoid factor must be a very small proportion of the total IgM.

DR. RHODES: Yes, there are two possible explanations: the rheumatoid factor is known to be one-tenth of the total IgM, and our method may not be sensitive enough to detect any rise.
Prof. E. G. L. Bywaters (Taplow): I should like to congratulate the authors on adding one more criterion to this nowadays rather difficult differentiation between the sexes. Has Dr. Rhodes any hypothesis to explain this difference?

DR. RHODES: No, I am afraid not.

DR. A. ST. J. Dixon (Bath): One of your most interesting observations was that the erythrocyte sedimentation rate seems to rise more in women that in men for a given immunological insult. One has to prove that men respond less to any given clinical situation with a lesser rise in the sedimentation rate than do women. Have you any observations on this?

Dr. Rhodes: No, we have not done this. We are continuing to work in the study, and we plan next to go into the Brucella phenomenon.

DR. J. S. LAWRENCE (Manchester): The rise in the rheumatoid factor titre may be one of the possible causes of false positive rheumatoid factor tests in the population. We have looked at this by comparing a number of people with these false positive tests with those having negative tests, and have found that Brucella antibody is related to the sheep cell agglutination titre, so that this is a confirmation. But other workers do not seem to have found a rise of the sheep cell titre on injecting Brucella; I am thinking particularly of some workers in Virginia. Can you tell us what dose was given?

Dr. RHODES: $0.5 \mathrm{ml}$. containing 1,000 organisms was given.

Dr. H. L. F. Currey (London): Was this a maximal dose? When looking for subtle differences between rheumatoid and non-rheumatoid patients, would one be more likely to expose them by using a maximal dose? Was there a difference in body weight between males and females or were they receiving relatively different body weight doses?

DR. RHODES: All the subjects were adult and obviously there were variations in weight. This was not a maximal dose, however, but a normal dose. This was not a vaccine in clinical use. It was imported from the U.S.A. where it was used experimentally only and this was the dose stated.

Suppression of Immune Responses in the Rat by Heterologous Anti-lymphocyte Globulin, by H. L. F. CURREY and M. ZIFF (Dallas U.S.A.): It has previously been shown that administration of heterologous (rabbit) antilymphocyte globulin (ALG) suppresses experimental adjuvant arthritis in the rat. Further studies have shown that this suppression was most efficient when ALG was given in a 3-day course bracketing the time of adjuvant injection. Later administration was less effective. However, slight inhibition was apparent even when ALG was given after the onset of arthritis. The antibody response to injected sheep erythrocytes was suppressed most markedly by ALG given before the sheep cell injection. All rats given adjuvant developed positive skin tests to tuberculin (PPD). ALG reduced the intensity of this reaction, but did not eliminate it, even in rats completely protected from arthritis.

Antisera raised separately against lymph node cells and against thymus cells agglutinated "lymphocytes" and "thymocytes" in the same dilution. There was no significant difference in the capacity of the two preparations to lower peripheral lymphocyte counts, suppress 
adjuvant arthritis, or inhibit immune responses.

Rats given ALG developed antibodies to rabbit globulin. The influence of such antiglobulin on the activity of ALG was studied by hyperimmunizing rats to rabbit globulin ALG administration. The presence of circulating anti-globulin caused no reduction in the capacity of ALG to reduce peripheral lymphocyte counts, suppress adjuvant arthritis, or inhibit immune responses. There was no evidence of renal damage in these or other rats given ALG.

Reference

Currey, H. L. F., and Ziff, M. (1966). Lancet, 2, 889.

Effect on Growth of Changing from Maintenance Oral Corticosteroid to ACTH Therapy in Still's Disease, by D. W. Zutshi, M. Friedman, and B. M. Ansell (Taplow): Five patients with severe Still's disease whose growth in height had been suppressed by prolonged but low dosage maintenance corticosteroid therapy were transferred to corticotrophin. Plasma cortisol levels were determined and results indicated that adrenal function was restured without difficulty. Treatment has been maintained for 7 to 10 months, and so far two children have shown an increased rate of growth in height.

Problems encountered include difficulty in controlling disease activity, both of eyes and joints, hypokalaemia, obesity, and hypertension. Before a definite conclusion can be reached, further careful observation in a larger series over a longer period of time is required.

Discussion.-DR. O. Savage (London): Changing patients from oral corticosteroids to ACTH is a difficult manoeuvre, as we have found in switching adults who bruised with oral steroids to ACTH.

There is also considerable variation in the length of time one has to continue ACTH before withdrawing corticosteroids completely, and the fact that in one of your patients the plasma cortisol was high 5 hours after an injection of ACTH and yet was low the next morning is an example of this. The probable explanation is that
ACTH stimulates the adrenal for only about 12 hours, so that the gland is left to run on its own for the second 12 hours. If it has been suppressed by long-term treatment it may return to this state for the second part of the day for a considerable period before eventually regaining its activity.

I feel you may be able to answer the vital question $\overline{\vec{S}}$ whether growth is inhibited by ACTH as it is by oral $\overline{0}$ corticosteriods only by comparing one group of children $\frac{C}{\partial}$ who have had only oral corticosteroids with another group $\overline{\bar{\omega}}$ who have had only ACTH. If one starts changing them from one drug to the other, a large number of $\varrho$ unknown factors are introduced.

DR. G. D. KersLeY (Bath): What was the time of administration of ACTH in the case treated with both $\overrightarrow{0}$ steroids and ACTH?

DR. FRIEDMAN: 9.0 a.m.

Rheumatoid Factor in Still's Disease, by E. J. HoL- 삥 Borow, D. W. Zutshi, B. M. Ansell, C. A. Reading, and W. V. EPSTEIN (Taplow): The results with the FII V haemagglutination test in Still's disease were reported. $\omega$ In 118 cases with active disease, the mean FII titre, $\underset{V}{ }$ although much lower than in classical or definite rheumatoid arthritis, was significantly higher than in 82 cases with inactive disease. It was also significantly higher $\frac{}{\supset}$ than in patients with other forms of arthritis, or in patients with other diseases, except acute rheumatic $\underset{\Omega}{\Omega}$ fever. In active Still's disease the latex test gave about twice as many (14/52) and the FII test about as three times $\overrightarrow{0}$ as many $(24 / 55)$ positives as the differential agglutinatiog test (8/52).

A talk was given by a patient on "What Still's diseaş has meant to me."

A film on the McKee arthroplasty of hips was shown by G. P. ARDEN.

The following demonstrations were also shown:

A 10-year follow-up of rheumatic fever

Radiological recognition of Still's disease in adult life

Pathological demonstration of cervical spine changes in Still's disease

Eye involvement in Still's disease

Varieties of spinal ossification

Growth defects in Still's disease

McKee arthroplasty of hips

Platt arthroplasty of knees

Synovectomy of knees

Synovectomy and excision arthroplasty of MCP joints

Stapling of the epiphyses of knees in Still's disease

The use of the electronmicroscope in demonstrating immune damage

Mechanisms of autoimmune damage

Cell transfer in New Zealand mice

The antinuclear factor in rheumatoid arthritis

Some new auto-antibodies

The F.II Test

Lectin arthritis

The action of ultra-violet on collagen

Haptoglobin distribution in rheumatic diseases

Chondromucoprotein

Immune deviation

Experimental arthritis

The use of Alcian blue as a stain
G. T. Thomas

E. G. L. Bywaters and B. M. Ansell

E. G. L. Bywaters and G. Loewi

W. K. Smiley

E. G. L. Bywaters

B. M. Ansell

G. P. Arden and B. M. Ansell

S. H. Harrison

B. M. Ansell and M. J. Riley

G. P. Arden, B. M. Ansell, and

I. C. M. McLennan

J. Dorling

P. C. Brown and L. E. Glynn

A. M. Denman and E. J. Denman

E. J. Holborow and G. D. Johnson

C. A. Reading

D. P. Page Thomas

R. Consden

A. Howard

G. Loewi and A. Temple

L. E. Glynn and A. P. Nind

J. E. Scott 
Clinical Meeting.-The following papers were read at the Annual General Meeting on November 17 and 18, 1967:

Carbohydrate and Insulin Metabolism in Primary Gout. By J. A. Boyle, K. D. Buchanan, M. McKiddie, M. J. Jasani, H. W. Gray, I. M. D. Jackson, and W. W. Buchanan (Glasgow): Patients with primary gout tended to have higher blood sugar and plasma insulin levels following an oral $50 \mathrm{~g}$. glucose load and in the fasting state than normal weight controls. When the data in the gouty patients was compared to weight-matched, i.e. overweight controls, no differences were found. It is concluded that there is no disturbance of carbohydrate or insulin metabolism in patients with primary gout, when due allowance is made for the fact that the gouty patients tend to be overweight.

Distribution of Gout and Serum Uric Acid Levels in the Relatives of Probands with Gout. By J. Rondier and P.H.N.Wood(Paris and Manchester): Most family studies have taken gouty probands, unclassified, and have studied their first-degree relatives. On the other hand patients with gout show differences in the prevalence of such features as renal disease and hypertension, and more notably in their daily excretion of uric acid in the urine. In addition, a review of population data on the distribution of uric acid levels lends little support to the concept of a bimodal distribution; to examine first-degree relatives for the presence of hyperuricaemia as a threshold characteristic is therefore not very helpful.

In an endeavour to meet some of these objections, the probands of the Manchester Gout Family Study were reviewed. These, together with additional patients in whom urinary uric acid excretion had been studied, were taken as probands, and their families were surveyed, including second-degree relatives. This permits analysis of the results in terms of probands with high and low urinary uric acid excretion, and also in terms of the degrees of relationship to the proband, which is useful when considering a graded trait.

Discussion.-Prof. E. G. L. Bywaters (Taplow): Could Dr. Wood tell us more about the heritability factor-what it really means and how it is derived?

DR. WooD: The heritability factor is derived, like the value for $k$ suggested by Penrose, from the prevalence in the population and the prevalence in relatives, and is intended to indicate the maximum extent to which a genetic hypothesis could account for the prevalences observed. I stress "maximum" because, although the technique is called "heritability", it is really only an indication of familial aggregation. It is not solely genetic; environmental factors may come into it. The value $k$ of Penrose, which is just the ratio of "observed" to "expected", basically shows that the predisposition frequency for this disease is low and for that disease is high, which is not much more than is already known from the frequency of the disease. With low values of $k$ one may presume that genetics are not very important, and equally with high values that genetics are important, but I do not think either of those two conclusions is justified. To sum up, if we consider a spectrum of the extent to which heredity and environment contribute to a disease, the conventional spectrum between nature and nurture, then the heritability value gives you a rough indication of whereabouts on that spectrum the disease falls; a value of 50 per cent. means that genetic factors and environmental factors are probably contributing equally.

Prof. J. H. KellgRen (Manchester): In the paper, the heritability values for gout and hyperuricaemia were very different, hyperuricaemia being very much lower. Do you think that there is therefore another factor other than serum uric acid which is important in the genesis of gout? Is there another hereditary characteristic responsible for gout other than hyperuricaemia?

DR. RoNDIER: It is tempting to think that the other factor might be the tendency to develop inflammatory attacks.

DR. Woon: The heritability for hyperuricaemia was similar to that for gout. We were questioning whether one can validly consider the heritability of hyperuricaemia-you are only chopping off the upper end of the distribution. The heritability for serum uric acid levels is very much lower, and as a whole they probably do not contribute significantly to the inherited component of gout, with the reservation that there may be factors in particular families that do lead to hyperuricaemia.

DR. J. A. Boyle (Glasgow): In normal twins, in the males, we found no tendency for the variation in serum uric acid levels to be inherited, whereas in the females we did have some evidence of genetic control, so our findings tie in with yours on the serum uric acid values in men. I may not have understood your point about the correlation coefficient of $0 \cdot 14$ in the spouses; are you saying that this may explain some of the variance between the levels of serum uric acid in the husband and in the wife? I think that you must square that correlation coefficient to get the amount of the variance which it explains, and if you square 0.14 you get 0.0196 - in other words your observed finding may only explain the variance to 2 per cent. in the spouses.

DR. WooD: We suggested that squaring the correlation coefficient accounted for the observed variation in relatives because basically these heritabilities are correlation coefficients; crudely, the correlation coefficient is doubled and then turned into a percentage, and twice $0 \cdot 14$ is $0 \cdot 28$. In other words, when you reduce these indices to the same common factor, the serum uric acid heritability index is almost identical with the observed level in studies. The spouse correlation may be of about the same order as the first degree relative correlation.

Comparative Study of the Hypouricaemic Effect of Drugs influencing the Metabolism of Uric Acid. By F. Delbarre (Paris): There has been considerable progress in the treatment of gout, and it is now possible to bring most patients back to a state of apparent normality. Colchicine remains the main drug, and phenylbutazone and indomethacin are also excellent in the relief of the acute attack, and the institution of prophylactic treatment is a great advance.

Most work has been done in the metabolic field. Diet and diuretic therapy are rarely sufficient, and in gout with tophi and in these cases with a high serum uric acid, it is necessary to prescribe hypouricaemic agents. The 
uricosuric drugs are classically used, but today, drugs which inhibit the synthesis of uric acid are increasingly employed.

The role of these drugs is not yet clearly defined. Uricosuric drugs are contraindicated in cases with renal lithiasis, increased uric acid in the urine, or renal failure. They perhaps increase the risk of renal lesions in gout.

Oroturic acid acts at the beginning of the metabolic cycle. It is well tolerated and reduces the serum uric acid by about 25 per cent. when given in a dose of 2 to 4 g. per 24 hours.

Allopurinol, the principal inhibitor of xanthine oxidase, is well tolerated and the risk of xanthine deposits or xanthine stone formation is negligible. A dose of $200 \mathrm{mg}$. per 24 hours usually reduces the serum and urinary uric acid to normal, especially in cases with large quantities of urinary urates.

Oxypurinol, the hydroxyl derivative of the previous drug, has on the whole the same effect, but twice the dose is required.

Thiopurinol has also the same effect, but the resulting increase in xanthinuria is very slight.

Uricase acts by destroying uric acid which is then excreted as allantoin. A fungus preparation has given us excellent results. Theoretically, these drugs all have the same effectiveness, but some are contra-indicated in certain cases. The important problem is to discover whether their use, of necessity over a period of years, may give rise to iatrogenic complications.

In future these drugs will be given in combination, the use of small doses reducing the risk of complications from each individual drug.

Discussion.-Prof. E. G. L. Bywaters (Taplow): Could Dr. Rondier tell us something about the possibile antigenicity of uricase; how many cases have been thus treated and if he has seen any cases of sensitivity develop.

DR. RondiER: We have observed one case of severe allergic reaction to uricase with shock. It was observed in a patient with fungal cutaneous infection, so we thought that it was possibly an allergy of fungal origin. Since then we have always made cutaneous tests with uricase before use.

Prof. BYwaters: This was not quite what I was asking. I was asking for how long and in how many patients you have been able to continue using uricase injections before sensitivity developed, or if it developed.

DR. RONDIER: The longest treatment with uricase has been for 4 weeks without incident. The only accident which was the allergic one, was observed immediately.

Stomach and Small Bowel Involvement in Scleroderma. By R. Bluestone, P. Beck, V. Hoffbrand, P. Holt, M. MacMahon, and G. Neale (London): Although a well-recognized feature, gastrointestinal involvement in scleroderma may be occult and there are no reports of any comprehensive survey using modern techniques designed to detect stomach or small bowel involvement and malabsorption in this disease.

In a retrospective study of 43 patients with scleroderma, there was objective evidence of stomach or small bowel disease in 20 per cent., often asymptomatic. $A \stackrel{\text { गु }}{\bar{\Phi}}$ prospective study, using radiological, histological, and $\frac{\bigodot}{3}$ biochemical examination has been undertaken in patients admitted to hospital with scleroderma. The abnormalities and their clinical significance was studied in correlation with other manifestations of the disease.

Discussion.-Dr. J. Rotstein (New York): We have studied 55 patients out of a group of 85 with scleroderma. Our findings confirm those of Dr. Bluestone and his colleagues. We have a somewhat greater incidence of $\mathbb{\Phi}$ gastrointestinal disorder, possibly because we do motility studies on every patient; we find that motility studies $s$ are more sensitive than radiological studies and can $\vec{O}$ detect earlier changes. In our series, close to 60 per cent. have gastrointestinal involvement, which we believe $\vec{\omega}$ is the commonest symptom of stemic sclerosis, perhaps $\mathcal{O}^{-}$ more common than skin involvement, and may often be the dominant feature. We treat patients with steatorrhea $\bar{\alpha}$ with antibiotics, and most derive some relief of symptoms, is if not of the disease.

Seven cases of Microcrystalline Arthritis associated ${ }^{\circ}$ with Rheumatoid Disease: Discussion of the Relationship between the two Syndromes. By H. BLOCH-Michel, M. Benoist, J. Ripault, and J. R. Siaud (Paris): Seven 3 cases of microcrystalline arthritis (four cases of gout and three of chondrocalcinosis) associated with rheumatoid $\vec{\theta}$ arthritis were studied. The association of the twoos conditions was established by examination of the synoveg fluid.

Chronic polyarthritic forms of gout and pseudo-goo are well known, but well-documented cases of this $\frac{\partial}{\partial}$ association are, curiously enough, rare in the medical literature.

These cases raise important problems of pathogenesis. Coincidental occurrence cannot be excluded, but a cause $\overrightarrow{\vec{O}}$ and effect relationship seems probable. The theory of 3

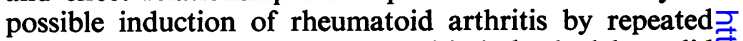
attacks of acute crystalline synovitis is backed by solido clinical and medical evidence.

It has been shown that the joint inflammation in microcrystalline arthritis leads to endocytosis of the microcrystals by synovial polymorphic cells. This 3 . phagocytosis leads to loss of cell granules with liberation of lysosomal hydrolases.

In clinical or experimental inflammatory polyarthritis the joint inflammation also includes a stage of phagocy-o tosis, also leading to liberation of lysosome material.

Intra-articular injection in experimental animals of streptolysine $\mathbf{S}$ or of filipin, substances capable of dis rupting the lysosomes, causes experimental arthritis, the histological lesions of which are identical with those of rheumatoid disease.

In accordance with Weissmann's theory, which sug- -0 gested a common ultimate final mechanism in all formse of arthritis, one may speculate whether repeated libera을 tion of enzymes during successive acute attacks of microcrystalline arthritis may not be capable of inducing rheumatoid synovitis.

Enzymatic changes in the synovial fluid would thuso set off a vicious circle. 
Discussion.-DR. J. S. LAWRENCE (Manchester): I am not convinced that the occurrence of rheumatoid arthritis and gout is more frequent than one would expect by chance. I have recently graded 52 cases of gout for rheumatoid arthritis and only one was given a definite grading for arthritis. One would expect at any rate two cases in such an age and sex distribution, so that one should reserve judgment about an association between the two.

Dr. H. L. F. Currey (London): Have you ever considered the possibility of putting urate crystals into the joint of a rheumatoid patient? It has been suggested that one reason why clear-cut rheumatoid arthritis and clear cut gout are seldom associated is that, when people who have the diathesis for both conditions develop crystal synovitis, this may initiate the sequence of events which you have described leading to the final common pathway of rheumatoid inflammation; the pattern of disease then follows that of rheumatoid arthritis and this is why one seldom sees the two together. This could be perhaps tested by following the course of synovitis in a rheumatoid subject following the injection of urate crystals.

DR. BENOIST: I hope I have understood. First, this association is probably a mere coincidence. I think it is very difficult to have strong views on this subject, though we have been struck also by Robecchi's findings of a surprisingly high percentage of rheumatoid factor in a survey of gout.

We have not studied the histological sequence of the injection of microcrystals into joints. Clinically, in five of our patients we can assume that the microcrystalline acute attacks preceded the chronic polyarthritis; these are patients whom we have followed during the entire course of their disease. Two were seen at a late stage and we are not able to tell you if the microcrystalline attacks preceded the chronic polyarthritis.

Natural History of Synovial Swelling of the Hand in Early Rheumatoid Arthritis. By A. KAY (London): The natural history of the synovial hypertrophy in the rheumatoid hand is of importance if the benefits of surgical treatment are to be assessed. The hands of 33 patients with definite but early rheumatoid arthritis were observed for a minimum period of 2 years, during which time three detailed assessments were made at approximately yearly intervals. The incidence and degree of joint involvement at each assessment was compared. The results suggest that synovial involvement occurs more frequently in the metacarpophalangeal joints than the proximal interphalangeal joints and that the incidence of spontaneous remission of synovitis is five times greater in the proximal interphalangeal joints than the metacarpophalangeal joints.

Discussion.-DR. G. E. EhrLICH (Philadelphia): I presume your dorsal wrist synovitis was the synovitis of the extensor tendons? Have you any figures on the extensor carpi ulnaris tenosynovitis which we feel is at least as common?

DR. KAY: In this part of the study the dorsal aspect of the wrist was considered as one. It is not always possible to separate dorsal tendon involvement from dorsal wrist involvement although the radio-ulnar joint can of course be considered separately.
Dr. B. M. Ansell (Taplow): Were there any erosive changes in the proximal interphalangeal joints that recovered? If so, what happened to the erosions?

DR. KAY: We have not yet analysed the $x$-ray changes in these joints. There were very few erosions observed. This will be the next instalment.

Dr. J. RotsteIN (New York): The last sentence brought out what may be the most important result of your findings. In the States some units are doing the earliest possible surgery, almost at the time of onset. We cannot tell the ultimate outcome, but certainly the second and third metacarpophalangeal joint and the wrist should be operated on as soon as possible.

DR. A. ST. J. Dixon (Bath): I should like to make a plea for as many physicians as possible to undertake studies of this sort. When surgeons claim to prevent disability by early synovectomy we have to be able to furnish evidence that, but for operation, disability would have followed. Certain patterns of joint and tendon involvement in the hand may be followed by disability, however good the surgeon. On the other hand, there is a very high remission rate in the proximal interphalangeal joints so that surgery is hardly justifiable. If we can identify some of those patterns in which synovectomy can prevent disability, we shall be doing our part in the exploration of the usefulness of synovectomy.

DR. J. GLYN (London): I've been forced by lack of facilities to study most of my patients without the benefits of surgery. A fairly substantial proportion of patients settle down with conservative treatment. I wonder if you have enough figures to say these second and third metacarpophalangeal joints are the ones that will remain obstinately swollen without surgical treatment. How many of yours did settle down? Have you any other explanation of this curious distribution of the first, second and third metacarpophalangeal joints apart from slightly increased use? It doesn't seem an entirely satisfactory explanation why these joints should remain particularly obstinate. When you do synovectomies of the proximal interphalangeal joints, do you get good functional results?

DR. KAY: The remission figures for the metacarpophalangeal joints are, I agree, relatively low, but with an increasing number in the series, now nearly 100 patients, this pattern seems to be consistent.

Dr. J. J. R. DUTHIE (Edinburgh): I think you are aware that there is a rather elaborate plan to evaluate this form of treatment, and until we have this kind of information it will be very difficult to pronounce. My own experience of watching hand surgeons at work would suggest that it is important not only to pinpoint where inflammation is, but what effect it is having on function. There are two indications for surgery-impairment or potential impairment of function, and pain; we see many very distorted hands where the tendons escape and you have a powerful grip, although some fine precision may be gone. It is much more important to assess whether synovitis is inevitably going to impair function or not. It can destroy bone and still leave good function, so that it is more complicated than just saying "these joints remain inflamed and these joints don't". I cannot remember exactly what your estimate of fiexor tendon involvement on the palmar surface was, but we have seen well over 50 per cent. of cases studied with flexor tendon involvement, and decompression of the carpal tunnel is one of the most important operations you can do. 
Staphylococcal Septicaemia complicating Rheumatoid Arthritis (Report of a Fatal Case with Purulent Arthritis of the Hip). By L. AuQuier, J. B. Paolaggi, B. Dastugue, and C. Rouques (Paris): This case of septicaemia complicating rheumatoid arthritis demonstrates the gravity of such an infection and the risk of joint suppuration. Infective arthritis is not always easy to recognize or to distinguish from an acute exacerbation of rheumatoid arthritis. A common therapeutic error is to increase the dose of steroids, if the general signs of infection are confused with the systemic effects of rheumatoid arthritis. A sudden deterioration in general condition and rigor requires a blood-culture to be performed, with aspiration of the joint, whether painful or not.

The prognosis is serious, for these infections are often unrecognized so that antibiotic treatment is started too late.

Steroid therapy is not necessarily the cause, for septicaemia and purulent arthritis have been observed in patients with rheumatoid arthritis who had not received corticosteroids.

Discussion.-DR. J. A. CosH (Bath): It is a good thing that Dr. Auquier should remind us of this complication which can arise unexpectedly in rheumatoid patients; we were originally alerted to this by Prof. Kellgren. I should like to describe a similar patient, a woman aged 57 with a 13-year history of rheumatoid arthritis who had been on prednisone for 3 years. Her terminal illness began with an increase in pain and swelling in the left shoulder. She then developed a discharging sinus, from which a staphylococcus sensitive to penicillin was grown, and penicillin treatment was started. During the second week we got a positive blood culture in spite of the antibiotic therapy and lumbar puncture showed an abnormal spinal fluid; then we noticed a systolic murmur at the apex, indicating vegetation on the mitral valve. She died soon after this and autopsy showed vegetation on a previously normal valve.

Prof. J. H. Kellgren (Manchester): This problem is common and important. It has been our practice since 1958 to consider septicaemia or bacterial infection in every patient with rheumatoid arthritis who deteriorates significantly, and early treatment is extremely effective. If any patient with rheumatoid arthritis suddenly "goes off" and has one or more joints which are more painful, it is obligatory to aspirate and culture them immediately. If bacterial infection is found and treatment is started immediately with systemic and intra-articular antibiotics (we use erythromycin intra-articularly as a first shot), many such infected joints make rapid recovery, and a potentially lethal illness becomes an unpleasant episode lasting a week. Once a virulent organism like the staphylococcus reaches the heart valves, the prognosis is bad; we have had two cases of the same kind.

Dr. A. ST. J. Dixon (Bath): This complication can occur in gout. Last week I carried out a post mortem on a patient who died with severe aortic incompetence and severe tophaceous gout. During life he had an effusion in one shoulder from which Pseudomonas aeruginosa was cultured. At autopsy, whereas all the other joints were white with urate deposits, the infected shoulder was clear of urates but showed the changes of severe inflammation.
DR. J. BALL (Manchester): About 1958 Blashford drew attention to the fact that pyoarthrosis occurs in elderly patients whether they have rheumatoid arthritis or not.

Dr. U. STEIGer (Basel): I am glad Dr. Auquier pointed out that it is not necessarily steroid treatment which causes these infections. I have reported four cases of infective joint disease in patients who had not had steroid treatment beforehand. I think such cases must be due to septicaemia, and one must emphasize that early treatment is important.

Dr. M. Thompson (Newcastle upon Tyne): We have had a patient with haemophilic arthropathy who had a spontaneous supperative episode in the knee joint. This can be difficult to diagnose because the bleeding itself may cause pain and inflammatory signs which mimic suppuration, and because there is a reluctance to introduce an aspirating needle.

DR. F. Coste (Paris): Have you seen staphylococcal N or other infections in rheumatoid patients treated with immunosuppressive drugs?

Dr. AUQUIER: No. We have had two additional cases; a 15-year-old girl with lupus erythematosus who died with staphylococcal septicaemia and infective arthritis of the hip, and a 25-year-old woman with a lupus-like syndrome who died of meningitis and staphylococcal septicaemia.

Reaction to Intradermal Injection of Human $\gamma$-Globulin in Rheumatoid Arthritis. By I. RoITt, C. SHAPLANR, and M. A. Chamberlann (London): Inflammatory re actions to aggregated IgG have been produced in the skin of human beings by Christian, and in the joints of patients with rheumatoid arthritis by Hollander and his colleagues. In view of these observations and of Glynn's hypothesis that these patients were sensitized to products of their own inflammatory responses, we have tried to investigate the response in the skin to injections of immunoglobulin $\mathbf{G}$.

Fourteen patients with rheumatoid arthritis, mostly sero-positive and mostly treated without steroids, were given intradermal IgG. Approximately $3 \mathrm{mg}$. of (a) native autologous IgG, (b) heat-denatured autologous $\bar{\sigma}$ IgG, and (c) heat-denatured pooled $\gamma$-globulin were injected into the patient's forearm. The erythema and $\bar{\rho}$ swelling which developed were observed and the whole experiment was repeated in normal people or those with osteo-arthritis, matched for age and sex.

Some erythema and/or swelling developed in all $D$ patients to all injections within the first half hour. This then subsided and a secondary reaction occurred between $\mathrm{N}$ 3 and 8 hours later. In the more severe reactions, $\sigma$ swelling and redness persisted for 24 hours. The response $\mathrm{N}$ to aggregated proteins was much greater than that to $N$ the native IgG. The patients with rheumatoid arthritis $\sigma$ did not react any more strongly to autologous aggregated IgG than did the control group. Similar results

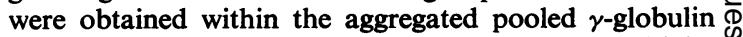
and this suggests that there is no specific hypersensitivity ? to the products of the inflammatory process in patients $T$ with rheumatoid arthritis.

A greater response was obtained both in controls and 
rheumatoids after injection of autologous heat aggregated IgG as compared with aggregated pooled $\gamma$ globulin. This is being examined further.

Discussion.-DR. J. BaLl (Manchester): Has an autologous serum been tried? Some results we have in animals bear out the observations that autologous $\gamma$ globulin can produce an inflammatory reaction in the skin. In small laboratory animals the skin treats autologous $\gamma$-globulin as it treats heterologous serum, but this is not true for the albumin; there seems to be something funny about the tissue's response to $\gamma$-globulin when it is separated from its own environment. The reactions may be related to the type of denaturation produced in the handling of the material, and it is noticeable in your observations that the greatest response was produced with the heat-aggregated Pool II. Pool II is unlikely to be a pure preparation of immunoglobulin G; our preparation had contaminants which may add to the denatured property of the material being tested and hence produce a greater response. I suggest that you are really only measuring the effect of your experimental procedure on the material being injected.

Dr. Chamberlain: We have not injected serum itself. We have used several sorts of pool preparations. The amount of aggregation may be relevant, and we are going to try to measure the degree of aggregation and the degree of complement-fixation to see if these tie up with the amount of reaction. We have used pooled serum from five blood donors processed in the same way as the autologous: the results suggest there may be a slightly increased reaction to autologous, but, as you say, it may be due to the method of preparation. The commercial preparation we get, which produces less inflammation than the autologous, comes from the Public Health Laboratory; its method of preparation is completely different from ours.

Brucella Infection of the Hip. By $H$. Serre and L. Simon (Montpellier): Seventeen cases of arthritis of the hip were seen among 72 patients with brucellosis involving bone or joint.

There were sixteen men and one woman, all aged between 20 and 40 years; the source of infection could usually be traced to occupational exposure or diet. Hip involvement arose usually between 3 and 6 months after the onset of infection, though sometimes as much as a year later. Certain abnormalities of the hip appeared to predispose it to infection.

The clinical picture is that of a sudden extremely painful hip lesion with low fever and severe disability. Radiological changes appear at least 3 weeks after the onset; decalcification is seen, either diffuse or localized, with slight erosions of the femoral head or acetabulum. Under antibiotic therapy, combined with a specific antimelitensis vaccine, clinical improvement was rapid, radiological improvement following more slowly.

With the exception of one patient who had a 13-year history of chronic brucellosis, resolution was satisfactory, without relapse and without residual functional disability. They had from 1 to 13 years follow-up. Only in one case with 5 years follow-up was subsequent degenerative osteo-arthritis observed.
One example of brucella arthritis was seen superimposed on an abnormal dysplastic hip. Brucella metitensis was found in the joint fluid.

Medical treatment is efficacious and surgery is not indicated.

Discussion.-Prof. E. G. L. Bywaters (Taplow): I should like to congratulate Dr. Simon and Prof. Serre on their excellent and complete coverage of this aspect of brucellosis. We do not see this often in Great Britain and we have little experience even of brucella abortus. I remember two cases; one woman with involvement of the ankle joint was interesting because we treated her with tetracyclines for a prolonged period without improvement, but when we added steroids she got better quickly on this combined antibotic and steroid treatment. Could Dr. Simon say anything about any additive effect that steroids might have in such infections?

Dr. Simon: No, we do not use cortisone in these cases.

DR. J. A. Cosh (Bath): Do your shepherds keep goats or cows in the Montpellier region? Presumably it is brucella melitensis; does it come from goats or from cows? Do you see brucella abortus infections?

Dr. Simon: No. Only brucella melitensis. We do not see brucella abortus or brucella suis.

DR. CosH: Chèvres ou vaches?

Dr. Simon: Sheep, goats, but no cows.

Urinary Hydroxyproline and Muscular Enzymes in Elderly Subjects. By A. M. ReCordier, G. SerRATRICE, J. B. Eisinger, R. AQuaron, and H. Roux (Marseilles): The study was carried out in a group of normal old persons (i.e. over 70 years of age) compared with a group of adult subjects and a group of old persons suffering from abnormal muscular weakness or senile osteoporosis.

In old but normal subjects the average value of urinary hydroxyproline output observed was $21 \mathrm{mg}$. a day. This value is slightly inferior to that of the adult subjects (29 mg. a day). The muscular enzymes determined (aldolase, pyruvate-kinase, lacticdehydrogenase, and creatine-kinase) did not differ in the two groups of adult and normal old subjects.

In old but pathological subjects presenting a pathologic, myogenic, and senile muscular weakness, urinary hydroxyproline was close to the values obtained in old but normal subjects but slightly less. In the same group the enzyme levels showed a gliding to mean values for aldolase and lacticdehydrogenase. Pyruvate-kinase was definitely lowered but creatinekinase was unchanged. In a group of subjects with senile osteoporosis, urinary hydroxyproline showed a very slight increase, much less evident than in osteomalacia affecting adults.

The definite decrease of pyruvate-kinase, in view of the part played by this enzyme in the producing of A.T.P., should be noted.

Discussion.-Dr. D. L. Gardner (London): Could you elaborate on the techniques used to take your muscle biopsies, and on the method used to preserve muscle enzymes? Was the weight of the tissue wet weight or dry weight, and did you make any measurements of tissue fluid? 
DR. Roux: The biopsy technique is surgical. We took a little piece of muscle, always from the peroneus longus, with local anaesthesia.

Dr. Gardner: And the measurements of fluid? Dry weight or wet weight?

DR. Roux: It was wet weight.

Electron Microscopical Study of the Phagocytosis of Urate Crystals. By K. T. RAJAN and A. M. GlaueRT (Aylesbury and Cambridge): Observations at the light microscopic level having shown that phagocytosis of microcrystals caused severe lysosomal changes, further studies were undertaken to examine in more detail the mechanism of degranulation culminating in cell death.

Microcrystals of sodium monourate were incubated with rabbit polymorphonuclear leucocytes obtained from induced peritoneal exudates at $37^{\circ} \mathrm{C}$. The cells were then fixed in 2.5 per cent. glutaraldehyde for 1 hour followed by 2 per cent. osmium tetroxide in veronal acetate buffer $\mathrm{pH} 7 \cdot 2-7 \cdot 4$ for 1 hour. After dehydration the cells were embedded in Araldite; thin sections were stained with uranyl acetate and lead citrate.

The results indicate that, in suspensions fixed after 5 minutes incubation, many polymorphonuclear leucocytes have already begun to ingest the crystals which become enclosed in membrane-limited vacuoles-the phagosomes. It appears that the granules fuse with the membrane of the phagosomes and discharge their contents into the vacuoles. In cells fixed after 15 minutes, the phagocytic vacuoles are larger and many cells are dead, probably owing to intracellular release of enzymes.

Discussion.-DR. K. D. MUIRDEN (Australia): Could you comment on the work done by Schumacher in Boston and by the Detroit workers studying leucocytes from the synovial fluid in patients with gout. These workers have shown electronmicrographs in which the leucocytes contain crystals which look at least twice the diameter of the cell and do not appear to be membrane-bounded. This has led to the suggestion that they may actually be formed or polymerized within the cell rather than taken up by simple phagocytosis.

DR. RAJAN: I have seen the pictures, which were published in the Annals of Rheumatic Diseases; some of the crystals have a phagosome but not others. We do not know what stage these cells are at. It is always difficult to make out the phagosome; I think there were three cells in one of the electronmicroscope slides where the cell shows a phagosome and the granule migrating towards its wall. It may be that you have to wait long enough. If you take cells out of the joint fluid you may see cells with the granules in various stages of migration towards the phagosome. Unless the granule fuses with the wall of the phagosome and releases its contents into the phagosome you would not expect to see the wall of the phagosome. It is an interesting idea that the crystals could be produced inside the cell. I have not seen any evidence of it in our work.

Prof. E. G. L. Bywaters (Taplow): Dr. Rajan has shown us a very beautiful histological sequence which he implies, as histologists usually do, is a time sequence.
Unlike the chap who punctures a gouty joint, he has a time base; he has a Time 0 when he injects his urate crystals. Has he studied the time sequence, withdrawing after certain intervals from these joints, and can he say what the actual timing of these events is-in real time, rather than histological time?

DR. RAJAN: In this study I have fixed the cells at $\stackrel{\oplus}{+}$ varying stages-some of the cells were fixed at 5 minutes and others at 15 minutes, after they had been incubated $\bar{\sigma}$ with the crystals. I have some time-lapse photographs $\overline{\bar{\omega}}$. with $16 \mathrm{~mm}$. where the crystal is ingested by the poly- $\vec{\nabla}$ morph and followed over a period of 15 minutes; once $\varrho$ phagocytosis occurs it is a matter of a few minutes. When you draw joint fluid out you may see cells in various $\overrightarrow{0}$ stages of phagocytosis.

DR. P. Holt (London): What happens if you put in a $\overrightarrow{\vec{\omega}}$ lysosome stabilizer?

DR. RAJAN: We have indirect evidence from using hydrocortisone and colchicine. Hydrocortisone, as you $\varrho$ know, stabilizes about 60 per cent. and colchicine about 30 per cent.; the colchicine-treated cells and also the ${ }_{\omega}$ hydrocortisone-treated cells do not degranulate readily. in This would probably be what you call the stabilizing $y$ action, preventing the granule from fusing to the wall of $\frac{1}{\sigma}$ the phagosome.

DR. HolT: I seem to remember that colchicine and true lysosome stabilizers such as cortisone have different ${ }^{-}$ morphological actions. Colchicine stops the migration of granules and cortisone acts by breaking them down.

DR. RAJAN: It acts at two levels, on the wall of the cell $\overrightarrow{0}$ and by stabilizing the lysosomal membrane. I haße confirmed this localization with a study using tritiated. colchicine; I have two slides showing the colchiciffe localized to the wall of the granule.

Senile Haemorrhagic Shoulder. By S. DE Sèze, ֻ̊ำ A. Hubault, and S. RAmpon (Paris): We have given the name "senile haemorrhagic shoulder" to a syndrome associated with ageing of the shoulder, the two main $\overrightarrow{\overrightarrow{0}}$ manifestations being osteolysis and haemorrhage. These 3 are associated to a varying degree, leading to a radio-? logical and clinical picture which varies from spontaneouso. haemarthrosis of the shoulder as described by Berman Sutro, Guariglia, and Banna and Hume Kendall in 1963, to the appearance of haemorrhagic senile "caries" described by us, in which the main sign is osteolysis of the greater tuberosity, sometimes even of the head of the humerus. The lesions are then sufficiently marked to suggest the diagnosis of tuberculosis or bone tumour.

Perforation of the rotator cuff is an important aetion logical factor, but haemorrhage also plays an important role in the early symptoms as also in the radiologica? and clinical progress of the osteolysis. These bonyt lesions favour the onset of haemorrhage but some authors have suggested that there is a haemorrhagic tendency due to age. In at least one of our cases sensitivity to aspirin and a low platelet count played an important part ${ }_{\sigma}$ On the other hand, haemorrhage within the bones favoured the development of osteolytic lesions.

In the very haemorrhagic forms, needle aspiration of the joint or even surgical drainage is no doubt a better ${ }^{+}$ form of treatment than infiltration with cortisone deriva=뭄 tives, as the presence of blood favours secondary infec tion. On the other hand, in the forms where blood is 
mixed with synovial fluid, one may attempt needle aspiration followed by infiltration which should however be abandoned if the synovial effusion continues. When the joint function is chronically and severely disturbed and there is a danger of osteolysis, the joint capsule may be repaired surgically using the minimum number of sutures.

Discussion.-Dr. Bourbier (Clermont-Ferrand): We have seen three haemorrhagic shoulders in three women aged about 60 , following some slightly more violent movement than usual. The diagnosis was made when serohaemorrhagic fluid was aspirated during local infiltration with corticosteroids. The patients improved after the infiltration. In two cases there was no radiological abnormality; the third showed osteoylsis in the region of the greater tuberosity.

DR. F. Coste (Paris): I have also seen a few cases of osteo-arthrosis complicated by intra-articular haemorrhage, in old women. The degenerative lesions in the superior part of the joint are the common site of the bleeding, and repeated haemorrhage with chronic haemarthrosis may aggravate the arthritis. Surgery may be required if the patients are not too old. One wonders if arthrosis of other joints may occasionally cause intraarticular bleeding. We have twice seen this complication occurring spontaneously in the knees. Among the factors predisposing to bleeding I mention the use of anticoagulants; in such patients a mild traumatic injury or the intra-articular injection of corticoid for arthrosis may be followed by synovial bleeding.

DR. M. Benoist (Paris): We have seen a similar case, an old nurse with a painful shoulder, and the joint aspiration each time showed blood. Several months later she was operated on and a synovectomy was performed, after which she completely recovered. Histological study showed typical changes of pigmented villonodular synovitis, and I should like to know if perhaps you are seeing pigmented villonodular synovitis in the shoulder joint.

PROF. DE SÈzE: In reply to Dr. Coste, our patients have not been treated with anticoagulants. I have already mentioned that the lesions of villonodular synovitis were not seen.

Prof. E. G. L. Bywaters (Taplow): Were any of these 12 cases bilateral?

Prof. DE SÈze: One case was bilateral. One shoulder just showed ordinary degenerative lesions in the cuff, and the other, which had a spontaneous haemarthrosis, showed osteolytic lesions.

DR. MelJers (Leiden): What position of the arm was used when the $x$ rays were taken? If the arm is rotated the picture is different; for example, external rotation gives the best view of the greater tuberosity.

Prof. DE SÈzE: We always used two projections-the anterior view, with the shoulder in internal and external rotation. Osteolytic lesions are much better seen in external rotation. It is important not to take the nonprojection of the lesser tuberosity for an osteolytic lesion when the greater tuberosity is projecting medially-one cannot infer from this appearance that there is osteolysis. One can only be certain that there is loss of the contour of the greater tuberosity when the film is taken in external rotation. We have made this a standard practice and whenever we mention osteolysis it is with this proviso.
DR. H. Wykeham Balme (London): Could these lesions be the result of scurvy?

PROF. DE SÈzE: No. The only haemorrhagic factor might have been aspirin in one case; we ruled out anticoagulants. Some authors have discussed a tendency to haemorrhage which comes with old age, but there is no proof of this theory.

DR. M. ThOMPson (Newcastle upon Tyne): I have seen three cases of this syndrome and in two there had been rupture of the acromial bursa or of the shoulder capsule with extravasation of blood into the soft tissues of the arm. Has Prof. de Sèze seen this?

PROF. DE SÈze: Yes. In several cases the swelling of the shoulder was accompanied by visible bruising under the skin and with extension of the bleeding into the soft tissues.

Osteodysplasty: Melnick and Needles' Syndrome. By F. Coste, P. MaroteauX, and L. Chouraki (Paris).*

Hereditary Periodic Oedema: Pathogenesis and Treatment. By J. Rotstein, S. C. Fell, and F. F. Foldes (New York) (introduced by Prof. E. G. L. Bywaters): Hereditary periodic oedema is a rare illness, the pathogenesis of which is unknown. A 17-year-old female had a mother and sibling also involved. Studies indicated a disorder of autonomic innervation of the smaller blood vessels. An effective method of treatment was evolved.

Discussion.-DR. F. Dudley HART (London): In the diagnosis one should consider lesions induced by the patient. I have seen recurrent buccal ulcers due to application of lighted cigarette ends, and ash could be seen at the edge of a recent ulcer. In another case recurrent cedema of the type described today was due to the tight folds of a nightgown acting as a tourniquet; the patient had been doing this for a year in an open ward, before it was discovered. I can't see any anatomical reason for a tourniquet distribution of the oedema unless it is due to a tourniquet. Were the lymphograms abnormal?

DR. RotsteIn: We thought about this and we had the first patient tested by a psychiatrist, but not the second. She was put in a Statue of Liberty cast and was watched intensively in the hospital. Angiograms showed no blockage. We do not understand this tourniquet-like distribution; it may have something to do with the distribution of the circulation in the lower ends of the extremities, but it is certainly tourniquet-like if you look at it. One has to be very careful about diagnosing periodic oedema and we are certainly aware of this. However, we were satisfied that this was not self-induced.

DR. R. M. MAson (London): I was surprised to find Bechet's syndrome on this list because the arthralgia and the joint symptoms are not periodic; but continuing, and this is a feature of Bechet's. Certainly the iritis and so on are recurrent, but I had not the impression that they were so regularly recurrent: is this a confusion with cyclical neutropenia, which of course does produce mouth ulcers?

DR. RotsteIn: You are right. This is not our classification, but in the literature Behçet's disease is included among the periodic diseases.

This paper is to be printed in full in the Annals with the discussion

$$
\text { 윽 }
$$$$
\text { 亨 }
$$ 
Prof. E. G. L. Bywaters (Taplow): I suppose by the same logic there is a case also for including rheumatoid arthritis in "periodic disease"; occasional cases of rheumatoid arthritis in the early stages have periodic recurrences at, say, weekly or 10-day intervals. Man has circadian and other rhythms built into his system and disease manifestations may well be affected by these internal rhythms. When we watch these patients in hospital the periodicity is seldom as accurate as the patient indicates in the history: very often we have hospitalized interesting patients with this periodic history to find that it is a matter of history only perhaps conditioned by the systematization of memory; the only way of ensuring that you know about the periodicity is to observe the patient. How many periodic episodes were actually observed in these two patients?

DR. Rotstein: We were a little sceptical at first, particularly as our patient had been seen by many people. She was observed for two periods before surgery because of our inability to decide what to do with her. The most striking thing was the exact 4-week recurrence in the other two limbs. If this patient does indeed have periodic oedema, she might have epiglottal oedema instead of oedema in the limbs. However, her insistence upon having the treatment and her subsequent well-being since -she would have been a narcotics addict otherwisejustify our rather severe treatment.

Arthropathy of Idiopathic Haemochromatosis. By E. Hamilton, K. Barlow, and R. Williams (London): A systematic joint survey was carried out on 32 patients with idiopathic haemochromatosis. Sixteen were found to have a significant arthritis, generalized in ten of whom six had involvement of the hip joints. In five patients the arthritis was less severe, being confined to the small joints of the hands, especially the metacarpophalangeal joints. The arthritis was primarily of a degenerative type, but in eight patients acute episodes of inflammatory arthritis had occurred, and some of them had been previously diagnosed as having rheumatoid arthritis. The striking radiological finding was the presence of chondrocalcinosis in twelve of the 32 cases, two of whom had no clinical arthritis. The menisci of the knee joints were calcified in eleven of these twelve patients, the triangular ligaments of the wrist in seven, the symphysis pubis in six, the hip joints in six, the metacarpophalangeal joints and ankles in four, the elbows and shoulders in three, and the metatarsophalangeal joints in two. In six patients there was slight calcification in some of the lumbar intervertebral disks.

In one case which came to autopsy there were speckled white deposits of calcium salts in the superficial layers of the hyaline cartilage. Crystals of calcium pyrophosphate were found in the joint fluid of one patient, and $x$-ray diffraction analysis of a meniscus showed a powder pattern consisting mainly of the triclinic dimorph of calcium pyrophosphate dihydrate, together with a small amount of the monoclinic dimorph. Chemical and neutron activation analysis of bone, hyaline cartilage, and meniscus did not demonstrate the presence of increased amounts of iron when compared with control subjects, although the patients had previously been venesected.
The patients with arthritis were older and had been $\frac{\vec{D}}{\vec{D}}$ known to have haemochromatosis longer than those $\frac{\varsigma}{3}$ without arthritis. The mean present age of the arthritic group was 64 years (standard error $2 \cdot 2$ ) compared with on 49 years (standard error $2 \cdot 50$ ) for those without arthritis, and the mean time from onset of first symptoms were 11 os and 4 years respectively. In eleven of the sixteen patients with arthritis the joint symptoms were first noticed $\frac{C}{0}$ after diagnosis of haemochromatosis. Venesection $\bar{c}$ therapy did not appear to prevent the development or progression of the arthritis.

Discussion.-PROF. S. DE SÈze (Paris): We are doing a similar study of 115 haemochromatosis patients but only $\vec{O}$ 32 have so far been studied completely. My collaborator, Dr. Hubault, will tell you what we think.

DR. A. Hubault (Paris): I have some slides of arthro- $\frac{\sigma}{}$ pathies of idiopathic haemochromatosis from our series. The appearances are similar to those shown by $\mathrm{Dr}$. in Hamilton. We have found two forms of radiological $v$ appearance: chondrocalcinosis similar to the idiopathic $\omega$ form, and changes in the bone and articular surfaces. N Of 32 cases of idiopathic haemochromatosis with

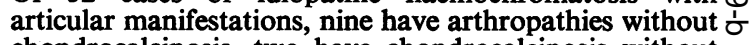
chondrocalcinosis, two have chondrocalcinosis without 0 other arthropathies, and two have both.

Dr. A. Rowatr Brown (New Zealand): Has Dr. $\vec{z}$ Hamilton seen relatives of these patients, especially
younger ones?

Dr. Hamilton: We have as yet seen only two relatives; $\vec{\varphi}$ we found no changes in them.

DR. K. D. MUIRDEN (Australia): In one of our cases $\frac{0}{\mathrm{Q} f}$ idiopathic disease, biopsy showed iron in the cartilage and not calcium. This was shown both histological and on ashing the cartilage. It may not always be appropriate to refer to the radio-opaque deposit in this condition as being due to calcification. I am sure that $\frac{O}{\mathcal{D}}$ most of these cases are calcified but in some perhaps the $\varnothing$ cartilage contains iron. With regard to the suggestion $\overrightarrow{\vec{P}}$ of Dr. Hamilton that these cases do not seem to improve with venesection: there is some biopsy evidence that they still have deposits of iron in the synovial membrane after enough venesection to deplete the liver of iron has? been carried on for a number of years. Has Dr. Hamilton had biopsies which show this apparent sequestration of iron in the membrane when the liver has been depleted ?:-

Dr. HAMILton: No. In two cases with arthritis that have come to autopsy iron was not present in the synovium, but we know that it has been found by other
workers.

DR. H. L. F. CuRREY (London): This paper emphasizes $\frac{\circ}{5}$ that one must screen all patients with chondrocalcinosis $\square$ for metabolic disorders such as haemochromatosis. Since our 35 cases were published, one has turned out to have haemochromatosis and I suppose others may do N so in the future. To what extent was the distribution of ${ }^{\circ}$ arthritis co-extensive with the radiological calcification? In some cases of chondrocalcinosis clinical arthritis may N appear in joints which are not radiologically calcified- $\omega$ and vice versa. Have you seen crystals in fluids from joints where there was no radiological calcification?

DR. HAMILTON: Six patients had widespread arthritis without chondrocalcinosis; in those with chondrocalcino- $\stackrel{f}{+}$ sis there was arthritis in, say, the small joints of the hand, especially the metacarpophalangeal joints, where radiolo- -0 gically there was no overt chondrocalcinosis. I have examined for crystals in only three cases because these 
patients present usually without acute crystal synovitis. We have seen only two patients, both previously suspected of having rheumatoid arthritis, with an acute attack of synovitis, although in six others there was a welldocumented history.

DR. P. Holt (London): Have you any idea what the mechanism is? What happens if you put iron into the joint in an experimental animal?

DR. Hamilton: We have no idea of the mechanism except that iron must be involved in some way; calcium pyrophosphate is normally broken down to orthophosphate and iron may perhaps inhibit the pyrophosphates from producing its deposition in the joints. It is very difficult to produce haemochromatosis in laboratory animals, although I understand this can be done using special techniques. We have not injected iron into experimental animals.

Dr. Seymour (London): We are proposing to do this in the rat to see if we can produce a haemochromatosis arthritis. I think the variation in the amount of iron present in the synovial tissue reported by different authors reflects the amount of venesection that the patients have had. It is easy to obtain a fall in serum iron before all the iron has come out of the tissues; if you wait awhile the serum iron will come up again as more comes out of the tissues. Our two patients had been extensively venesected and we were able to show no iron chemically or histologically.

DR. L. Simon (Montpellier): We have found four cases of arthropathy in twenty cases of primary haemochromatosis. In another case of diabetes mellitus with chondrocalcinosis and arthropathy, liver biopsy revealed haemochromatosis without skin pigmentation or hepatomegaly. The combination of isolated diabetes mellitus and chondrocalcinosis with arthropathy suggests haemochromatosis.

Transient Idiopathic Osteoporosis of the Hip.* By M. LeQuesne (Paris).

*This paper is to be published in full in the Annals with the discussion thereon.
Arthritis of Familial Mediterranean Fever: Further Experiences. By G. E. Ehrlich (Philadelphia). The prevalence of familial Mediterranean fever among Sephardic Jews in Israel permitted definition of the articular symptoms and signs. Involvement was usually monarticular and occurred at unpredictable irregular intervals, accompanied by fever. Local signs were marked tenderness and swelling, with relative absence of redness and warmth of the joints. Though attacks were usually of short duration, some were prolonged, but all spontaneously subsided and led to complete functional recovery. Further patients have been examined in the United States; in most cases, these too were usually Sephardic Jews when the cases were familial. Sporadic cases have been seen in patients of other nationalities, suggesting intriguing historical speculations about their ancestry.

Discussion.-Dr. D. A. Brewerton (London): We have had two such patients referred for diagnosis from the Middle East. The first was referred with a diagnosis of ankylosing spondylitis; he had fever, recurrent acute abdominal pain, and skin lesions. I should like to describe a Protestant family from Essex, who seem to have none of the connexions that Dr. Ehrlich was referring to. The ten patients involved had had recurrent acute attacks of arthritis starting early in childhood and in most instances going on for the rest of their lives, exactly like familial Mediterranean fever; seven can produce skin lesions by exposure to cold and can even produce acute arthritis either by cold weather or by application of cold to a joint. I hesitate to say this is familial Mediterranean fever, but it raises the question where to draw the line.

DR. EHRLICH: Many of my patients have also had precipitating features. In some cold has been effective and in others, trauma, forced marches, and the like, but in others heat. In these particular families there is no consistent precipitating factor even though a specific precipitating factor does tend to run in families.

\section{AUSTRALIAN RHEUMATISM ASSOCIATION ANNUAL MEETING, 1967}

The Annual Meeting of the Association was held in Melbourne, on October 9 to 11, 1967. The following papers were presented:

Rheumatoid Heart Disease. DR. IAN FERgusON (Brisbane): A detailed case history of a young female patient with aortic valve disease and myocarditis.

Arthritis, Tenosynovitis, and Agammaglobulinaemia. DR. Hugh Gallagher (Sydney): A 64-year-old man with a 32-year history of broxchopneumonia, sinusitis, and diarrhoea developed arthritis and tenosynovitis of rheumatoid type. He had a low level of IgG with absent IgM and IgA. IgG and IgA levels were raised separately in two relatives, whereas seventeen relatives were completely normal.

Arthropathy in Renal Failure. Dr. Henry Stonnington (Sydney): Cases were described with long-standing renal failure and phosphate retention with attacks of acute arthritis. $X$ rays revealed calcific deposits around 